\title{
Improving Anesthesia Safety in Low-Income Regions of the World
}

\author{
Isabeau A. Walker • Tom Bashford • \\ J. E. Fitzgerald $\cdot$ Iain H. Wilson
}

Published online: 15 March 2014

(C) Springer Science + Business Media New York 2014

\begin{abstract}
Safe anesthesia is dependent on a skilled clinician, a functioning anesthesia machine, monitoring equipment, drugs and a healthcare facility with support services and staff. In high-income regions we expect a quality service with excellent levels of safety. In lowincome countries, competition for healthcare resources is significant, and surgery has been neglected as a component of public health services. Anesthesia is relatively expensive because of the high cost of imported equipment and drugs, and underinvestment is common. Small numbers of inadequately resourced providers struggle to deliver a service sometimes associated with alarmingly high mortality rates (as much as 1,000 times higher than in the best centers). These factors impact on development of the specialty and recruitment and training, creating a dangerous situation for patients. We review published data on anesthesia services in low-income regions, describe the difficulties, analyze where improvements should be prioritized and make
\end{abstract}

\footnotetext{
I. A. Walker $(\bowtie)$

Department of Anaesthesia Great Ormond Street Hospital NHS Foundation Trust, UCL Institute of Child Health, Great Ormond Street, London WC1N 3JH, UK

e-mail: isabeau.walker@gosh.nhs.uk

T. Bashford

Department of Anaesthesia, Cambridge University and Cambridge University Hospitals NHS, Foundation Trust, Hills Road, Cambridge CB2 0QQ, UK

e-mail: tom.bashford@doctors.org.uk

\section{J. E. Fitzgerald}

Lifebox Foundation, 21 Portland Place, London W1B 1PY, UK e-mail: ed@lifebox.org

I. H. Wilson

Department of Anaesthesia, Royal Devon and Exeter NHS Foundation Trust, Barrack Road, Exeter EX2 5DW, UK
}

recommendations to improve anesthesia safety in poorer regions of the world.

Keywords Safety $\cdot$ Low-income countries $\cdot$ Health infrastructure - Resources · Training - Anesthesia equipment · Quality improvement

\section{Introduction}

Safety has been a concern of anesthesiologists since the early days of the specialty. The first large-scale reviews of anesthesia outcomes published in the 1940s and 1950s recognized the risks associated with anesthetizing acutely ill patients in poor condition, the problems with monitoring respiration, particularly detecting cyanosis, and the risk of death due to anesthesia (estimated then to be 1:2,000 anesthetics) $[1,2]$. Anesthesia-related deaths, largely related to airway obstruction or medication errors, were deemed avoidable with appropriate training, and anesthesiologists were encouraged to investigate and share learning so that others in the profession could avoid making the same errors [3]. Over the ensuing decades, anesthesiologists have been at the forefront of attempts to standardize care, improve monitoring, develop new drugs and provide high standards of training and education. The US Institute of Medicine Report, 'To err is human,' singled out anesthesiology as an example of good practice because of the impressive improvements made in patient safety, with the risk of anesthesia-related mortality said to have been reduced from $1: 10,000$ in the early 1980 s to $1: 200,000$ in the 1990s [4-6].

In contrast, in poorer parts of the world, surgery has been neglected as a component of public health services, and improvements in anesthesia safety seen in high- and 
middle-income countries have not been realized. In this review we will describe the current state of anesthesia care in low-income countries (LICs), and consider possible solutions to improve anesthesia provision and outcomes.

\section{Anesthesia-Related Mortality and Development Status}

Bainbridge et al. [7••] performed a systematic review and meta-analysis of studies published up to 2011 that considered perioperative and anesthetic-related mortality. Studies were included if they had a sample size $>3,000$ and if raw data, including denominator data, were available. The definition of primary outcomes varied among the different studies, but most reported outcomes within the first $48 \mathrm{~h}$ of surgery. Combining studies from all regions of the world, the risk of dying during surgery with anesthesia as the sole cause declined significantly over time, from 357 deaths per million operations before the 1970s (approximately 1:2,800), to 52 per million in the 1970s-1980s $(1: 19,230)$ and 34 per million in the 1990s-2000s $(1: 29,400)$. The reduction in mortality over time was highly significant $(p<0.00001)$. Sicker patients (as expressed by the ASA score) had a greater risk of perioperative cardiac arrest or all-cause perioperative mortality. The study also related anesthesia outcomes to the development status of countries, reporting them using the UN Human Development Index (HDI), an index based on life expectancy, literacy, enrollment in further education and per-capita income. When considered separately, the reduction in anesthesia risk was only seen in high HDI countries (HDI $\geq 0.8$. The risk of death where anesthesia was identified as a contributory factor also decreased significantly over time, but again, only in the high HDI countries. In low HDI countries (HDI $<0.8$ ), the risk of mortality where anesthesia was a contributory factor actually increased over time. Combining patients of all ASA grades, the risk of death due to anesthesia as a sole cause in the 1990s-2000s was 1:40,000 in high HDI countries and 1:7,000 in low HDI countries. Publications from Zambia, Malawi, Zimbabwe and Togo were excluded from the Bainbridge study because of their small size, but reported an even greater risk of anesthesia-related mortality, between 1:133 and 1:1925 [8-13].

Many deaths in the smaller studies were related to hypoxia or hypovolemia, which the authors suggest could have been prevented with investment in functioning healthcare systems, training and equipment [8-13]. A study of patients undergoing cesarean section from Malawi described a $1.05 \%$ overall mortality rate, with lack of anesthesia training also identified as a particular risk factor [14]. Spinal anesthesia is often considered the technique of choice for obstetric anesthesia in low-resource areas, as it is a simple technique to learn and requires a minimum of equipment [14]. However, the fifth Comprehensive Report on Confidential Enquiries into Maternal Deaths in South Africa published in 2012 described a substantial number of deaths due to spinal anesthesia (73 of the 92 direct anesthesia deaths), the majority occurring in level 1 district hospitals in rural areas, mainly associated with severe uncorrected hypotension or hypotension/high motor block [15••]. Important governance issues were identified, including failure to ensure a supply of essential drugs, lack of on-going maintenance and replacement of equipment, and inadequate numbers of competent staff. The authors concluded that poorly managed spinal anesthesia may be directly responsible for maternal deaths and should not be assumed to be safer than general anesthesia in resource constrained settings.

\section{Poor Access to Surgery}

In 2008, Weiser described a major discrepancy in access to surgery between high, middle and low-income countries [16••]. The global volume of surgery was estimated from surgical data and related to per capita expenditure on healthcare in the WHO member states. The global volume of surgery was large (estimated 234 million major surgical procedures per year), but most surgery was performed in wealthier parts of the world. Countries with low expenditure on healthcare ( $<\$ 100$ per head annually) accounted for only $3.5 \%$ of surgical procedures, even though they included $34.8 \%$ of the global population, while countries with high expenditure on health $(>\$ 1,000$ per head annual healthcare expenditure) accounted for $73.6 \%$ of procedures and $30.2 \%$ of the global population.

Poor access to surgery is likely to contribute to high surgical mortality, particularly for those living in rural areas, and also contributes to maternal and newborn deaths $[17,18,19 \bullet, 20,21 \bullet, 22-24]$. The ideal cesarean section rate at a population level has not been clearly defined, but a lower limit of at least $5 \%$ is thought to be necessary to protect maternal and newborn outcomes (complications such as complete placenta previa or obstructed labor occur in 1-2 \% of pregnancies). A recent review of published rates of cesarean section described rates of less than $5 \%$ in 18 countries in southern Asia and sub-Saharan Africa, with extremely low levels in some countries (less than $2 \%$ in 10 countries in sub-Saharan Africa) and in poorer populations (less than $1 \%$ for the poorest $20 \%$ of the population in 12 study countries) [25*0]. The low rates of cesarean section were attributed to infrastructure deficiencies and poor access to basic surgical services, which the authors suggested contributed to the high maternal and newborn mortality recorded in these populations [25••]. 
In many district/rural hospitals where surgical services are poorly developed, cesarean section represents the most common major surgical procedure performed. Two groups have suggested that the ratio of cesarean section to major operations is a useful proxy index to describe the provision of surgical services in a particular country, district or hospital and can be used to track improvements in these services; a high ratio of cesarean section to major surgery describes a large unmet general surgical need [26•, 27•, 28]. Of note, cesarean section accounts for approximately $29 \%$ of total surgery in Ethiopia [24] and 14-63\% of surgery in district hospitals in Uganda, Mozambique and Tanzania [17], again illustrating the enormous unmet need for surgery in these countries. The unmet need is likely to be particularly high in countries such as Ethiopia where a cesarean rate of less than $0.6 \%$ has been recorded [24].

From a patient perspective, lack of access to elective and emergency surgery and limited trauma care translates to high levels of disability and many unnecessary deaths. The Surgeons OverSeas Assessment of Surgical Need (SOSAS) has been developed to assess the prevalence of surgical conditions and the unmet surgical need in low- and middleincome countries [21••]. A cluster randomized cross-sectional survey of 1,843 households in Sierra Leone suggested that $25 \%$ of 3,645 respondents interviewed had an untreated surgical condition and that $25 \%$ of deaths occurring in the respondent's household during the previous year may have been averted by surgery in the week before death, most commonly to treat abdominal distension or pain, bleeding or illness during childbirth, or trauma. Respondents in rural areas were more likely to be in need of surgery than those in urban areas. The survey tool was also used in 1,626 households in Rwanda; $6.4 \%$ of respondents had a current surgical condition, and $33 \%$ of deaths in the household in the previous year may have been related to a surgical condition [20].

The World Bank sponsored Disease Control Priorities publication in 2006 estimated that $11 \%$ of the global burden of disease is due to conditions that can be treated surgically [29]. The impact of disease expressed in disability adjusted life years (DALYs), the sum of years of life lost due to injury (YLL) and years lived with disability (YLD), is used as an outcome measure in the recently updated Global Burden of Disease study [30]. This showed that injuries contribute to $11 \%$ of DALYs globally, with road traffic accidents the 10th most common cause of DALY [30]. Surgery can no longer be considered a luxury in public health terms, and indeed, in terms of cost/DALY averted, surgical interventions compare well with other public health interventions, for instance oral rehydration therapy, vitamin A supplementation or anti-retroviral therapy for HIV [29]. It has been recommended that elective surgery for common conditions, such as hernia, cataract, clubfoot, or cleft lip and palate, and emergency surgery for the acute abdomen, obstetric complications and trauma should be prioritized within public health programs [29, 31••].

\section{Inadequate Infrastructure to Support Surgery}

Successful surgical intervention requires an efficient anesthesia service. Anesthesia is a clinical specialty dependent on technical resources including equipment, drugs and trained anesthesia providers. The World Federation of Societies of Anaesthesiologists (WFSA) and the WHO have described minimal standards for anesthesia in small health centers, district hospitals and referral hospitals $[32 \bullet \bullet, 33]$. The standards describe the level of training for anesthesia personnel and the essential drugs and equipment, both disposable and non-disposable, required for the scope of work being performed. Without the basic facilities described, safe anesthesia cannot be provided.

Unfortunately, in many LICs, the current lack of surgical provision at both local and district hospital level means that when patients present, often with advanced pathology, facilities are poorly equipped and so unable to provide the care that is needed, particularly in the rural areas.

Within the last decade, there have been many studies that have described the state of healthcare facilities and availability of trained anesthesia providers in LICs. A questionnaire survey of anesthesia providers in Uganda in 2006 suggested that only $23 \%$ of providers had the facilities to deliver safe anesthesia to an adult, $13 \%$ to deliver safe anesthesia to a child and $6 \%$ to deliver safe anesthesia for a cesarean section [34]. The survey was repeated at hospitals in rural southwest Uganda in 2008, when it was found that only 29 of 72 hospitals that should have been able to undertake surgery were able to do so, mainly due to a shortage of essential personnel (anesthesia provider or surgeon). None of the hospitals undertaking surgery consistently met the minimum standards described by the WFSA and WHO [19•]. Similar surveys have now been completed for more than 800 facilities in at least 24 lowand middle-income countries (LMICs), using a questionnaire based on the WHO Integrated Management for Emergency and Essential Surgical Care (IMEESC) toolkit [35-46], the PIPES tool (personnel, infrastructure, procedures, equipment, supplies), developed by Surgeons OverSeas (SOS) [20, 47-49], or a tool developed by the Helfen Beruhrt Study Team [45-51]. All studies demonstrate, not unsurprisingly, that where the healthcare budgets are inadequate, maintaining a skilled workforce and wellequipped hospitals is impossible. Basic infrastructure requirements such as running water, electricity and oxygen are not consistently available, particularly in rural areas or 
in countries with low per capita health expenditure. Ketamine, spinal anesthesia and general anesthesia are used commonly, but anesthesia equipment, such as anesthesia machines, monitoring and airway equipment, particularly for children, is often not available in rural centers. A review of 590 facilities in 22 LMICs showed that $55 \%$ did not have reliable access to oxygen supplies (cylinder or oxygen concentrator), and $40 \%$ did not have a functioning anesthesia machine [44]. Access to opioids is a particular problem, and it has been estimated that $85 \%$ of countries do not have access to adequate supplies of morphine because of concerns about addiction and abuse [52].

Pulse oximetry has been identified as a standard of care by the WHO, WFSA and in all countries that have national anesthesia standards, and pulse oximetry has been suggested as a surrogate measure of the availability of essential equipment for operating theatres. Funk et al. [53•] estimated that $51-70 \%$ of hospitals in sub-Saharan Africa did not have access to a pulse oximeter, illustrating the challenge inherent in equipping operating theatres in many LMICs. The authors suggested that 2 billion of the world's population did not have realistic access to a safe surgical facility (less than two operating theatres per 100,000 population) $[53 \cdot]$.

\section{Lack of Trained Workforce}

The global deficiency in healthcare workers is well described, as is the problem of medical migration [54-56]. There is an estimated shortfall of 720,000 physicians and 670,000 nurses required to provide basic health services in sub-Saharan Africa, and a strong negative correlation between numbers of physicians and maternal mortality rate, independent of per capita income, poverty or female literacy [57].

Numerous surveys of facilities have confirmed that anesthesia is largely delivered by a non-physician workforce, nurses or clinical officers, and in population terms, with very few anesthesiologists compared to high-income countries [20, 35-51, 54, 58]. Where anesthesiologists are available, they are mainly based in larger regional or referral hospitals in urban centers.

Increasing the number of trained personal through task shifting is often recommended as a solution to this workforce crisis, but in anesthesia, task shifting occurred decades ago, particularly in sub-Saharan Africa. Non-physicians, either nurses or clinical officers, are the main anesthesia providers, often after limited training, with no access to on-going support supervision, books or continuing professional development $[20,35,50]$. Low numbers of anesthesiologists and lack of anesthesia advocacy may account for some of the infrastructure deficits seen in some countries. The relationship between task shifting and the high anesthesiarelated mortality found in LIC is not clear, although the outcomes must be better than the alternatives, which are long delays or no anesthesia service at all $[14,56]$. Extreme shortages of anesthesia providers has led to another cadre, the 'trained on job' anesthetist, who has received no formal training but is trained of necessity in facilities where there are only one or two providers [14, 19•, 34, 50, 59]. Fenton identified limited training as one of the important factors associated with maternal death after cesarean section [14]. The South African maternal mortality report suggested that even intern doctors with comprehensive undergraduate training are not necessarily able to translate their theoretical knowledge into practical anesthesia skills [15••].

\section{Lack of Resources}

Major improvements in anesthesia safety in low-income regions of the world will only be possible when both surgery and anesthesia are recognized as being an integral part of comprehensive public health services. Resources are clearly a limiting factor; in 2011 the per capita expenditure on health in the UK, Germany and France was $\$ 3,609$, $\$ 4,875$ and $\$ 4,952$, respectively, compared to $\$ 89, \$ 31$ and $\$ 45$ in Zambia, Malawi and Togo [60]. Most hospital expenditure relates to staffing, and these costs are obviously much lower in LICs, but even so, the expenditure on surgical services is disproportionately low, compared to other health service expenditure. The Bellagio Essential Surgery Group (BESG) estimated the per capita spending on surgery in six government district hospitals in Uganda, Mozambique and Tanzania in 2007 ranged from \$0.05 to $\$ 0.14$, excluding out of pocket expenditure by patients and capital costs. Hospital expenditure on surgery represented 10-14\% of inpatient expenditure, with hospitals relying on external donations for essential equipment such as an operating tables and theatre lights [58].

\section{Improving Anesthesia Safety in Low-Income Countries}

Drawing together the reviews and information described above, it is not surprising that anesthesia outcomes in LICs have not improved in recent decades. Lack of access to surgery is a major problem; patients are sicker when they present for surgery, with higher ASA grade and hence increased risk. Economic constraints and weak governance play their part. Providers with a minimum basic training struggle to provide care for patients of high acuity, often without access to even the most basic of resources. The requirements for safe anesthesia are well described, and we suggest the following areas need to be addressed: 
1. Investment in surgical care

2. Investment in training and workforce

3. Investment in technology and infrastructure

4. Improving the quality of existing services

\section{Investment in Surgical Care}

If anesthesia safety is to be improved, the first priority is investment in cost effective surgical care in LICs [31, 58]. A number of recent initiatives may improve future funding for surgery. The United Nations 'Global Thematic Consultation' was completed in 2013 with the aim of identifying development priorities post 2015 [61]. Strengthening health systems, universal health coverage and equity of access were identified as health priorities as well as the existing health Millennium Development Goals (MDG) for maternal and newborn health. While not targeting surgery specifically, investment in health systems, national ownership of the agenda and global partnerships were identified as key drivers [61].

The recently launched Lancet Commission on Global Surgery is particularly timely. The aim of the Commission is to bring clinicians and public health experts together to address the unmet global burden of disease due to surgical conditions and to provide consensus recommendations for funding, provision and governance of surgical care, define clear metrics to track surgical care structure, process and outcomes, and consider the research agenda for global surgery [62•]. The Disease Control Priorities Project (DCPP) published by the World Bank is due to be updated in 2014, and it is hoped will also help define priorities for surgery in LICs [63].

The requirements for anesthesia have been defined for different settings [32••], but, although obvious to anesthesiologists, this information needs to be presented in terms of cost effectiveness for public health comparison. Anesthesiologists should be mature in the way that they present their specialty, particularly where resources are limited, so that policy makers make appropriate investments [64]. The appropriateness of DALY-based metrics has been questioned for surgical interventions, and alternative metrics based on prevalence, backlogs to treatment, and disability incurred by treatment delays have been suggested [65]. Appropriate metrics to assess anesthesia provision at a population level are also required.

\section{Investment in Training and Workforce}

Improvement in anesthesia safety requires investment in training and training capacity for both medical and nonmedical anesthesia providers, with an assessment of need in terms of numbers required for the health system. Access to continuing professional development, on-going clinical supervision, acceptable working conditions, career progression and adequate remuneration are all essential if trained healthcare workers are to be retained $[13,55,56]$.

The work involved in training includes curriculum development, sourcing educational materials, assessment methods, teaching in the workplace and continuous professional development. The duration of training for anesthesiologists varies from 3 to 8 years, for non-medical providers 6 months -3 years. However, length of training is no guarantee of quality. In most high-income countries training programs are the result of decades of development with many resources having been invested. National standards have generally been developed through professional colleges or national societies-countries vary from one to another. In places with low numbers of practicing clinicians, the workload required to ensure training may be impossible to meet alongside busy clinical jobs. Journals offering free access to their content for those in LIC have a key role to play, and the Internet offers unprecedented opportunities to distribute anesthesia resources. However, a curriculum cannot simply be transferred from one setting to another-the educational standards at entry to training may vary, as well as the requirements in the destination hospital.

There are striking positive examples of how some countries, regions and programs have succeeded, for instance the Faculty of Anaesthetists of the West African College of Surgeons (http://www.wacs-coac.org), advances often achieved by those returning after completing training fellowships out of country. The World Federation of Societies of Anaesthesiologists (WFSA-www.wfsahq. org) has supported anesthesia training in LIC since inception and provides a source of educational materials, training fellowships and international standards for anesthesia. The WFSA also coordinates a Train the Trainers course to assist in educational development and links the many other national and regional societies that support anesthesia training beyond their borders.

Partnerships between professional organizations and between institutions can make an important contribution to anesthesia training programs. They are not a panacea, but can provide short-term support while growing local capacity. Newton has described a model for training nurse anesthetists in Kenya, with nurses referred from rural hospitals to a regional non-government hospital for training. The 16-month curriculum was developed to reflect local surgical conditions and the facilities available in the community hospitals [66•].

The Ugandan Society of Anesthesia and the two main training institutions in Uganda, Mulago Hospital and Mbarara University Hospital have formed partnerships with the Association of Anaesthetists of Great Britain 
Ireland (AAGBI), Global Partners in Anesthesia and Surgery (GPAS) and Massachusetts General Hospital in the USA, and St. Joseph's Health System International Outreach Program in Canada and others, which have transformed anesthesiology training in Uganda. Anesthesia was previously unpopular as a physician specialty, with many graduates preferring to train in surgery or public health because of higher status or salary associated with externally funded projects. The drive to improve training has been coordinated and led by the anesthesiology leadership in the two departments of anesthesiology in Uganda. Interventions have included top-up salary support for trainees, large scale donation of new textbooks and e-learning materials, hands on training by visiting faculty, scholarships for Ugandan anesthesiologists to train in Canada and support for long-term volunteers in Uganda, and more recently, development of research partnerships and training courses for clinical officer anesthetists [67•, 68•]. This has resulted in a major increase in recruitment to physician anesthesia in Uganda, from two trainees in 2006 to 43 trainees up until the end of 2013, with Ugandantrained anesthesiologists now leading outreach training courses in obstetric anesthesia for anesthetic officers, funded by UK Aid [69]. Similar initiatives to support anesthesiologist training have been developed between the Canadian Anesthesiologists' Society International Education Foundation (CASIEF) and Rwanda [70•], and more recently, as a partnership between the UK and Zambian governments to support anesthesiology training in Zambia [71•]. If effective, partnerships, like friendships, will be longer lasting than the projects alone, but they need support from local Ministries of Health if positive impacts are to be sustained.

\section{Investment in Equipment and Hospital Infrastructure}

Internationally, the anesthesia equipment market is dominated by a few firms developing and selling complex products to meet anesthesia needs in high-income countries. There has been minimal investment into technology that is low cost, robust and functional in more austere environments. Modern large-scale procurement processes are frequently inaccessible to small and remote hospitals, and perversely, many have to pay more for an item of equipment that well-resourced Western centers are able access at lower cost. This also applies to essential drugs, disposable and specialist anesthesia equipment and monitors.

The poorer economies are not an obvious investment target for large global companies, yet hospitals in these countries represent a huge potential market for development. However, it is essential that international procurement processes address infrastructure requirements, particularly in relation anesthesia equipment, for instance the need for reliable electricity supply, a secure supply of pressurized oxygen and maintenance. Unless this is ensured, large sums of money will be wasted, and the desired improvements in anesthesia safety will not be achieved. It is welcome in this respect that an ISO standard has been published for anesthesia machines for use in areas with limited logistical supplies of electricity and anesthetic gases, and an ISO standard for draw-over anesthesia systems is in preparation [72]. Oxygen concentrators have been suggested as the most reliable, cost-effective way for hospitals to access oxygen, and a call has been made to place oxygen supplies higher on the global health agenda [73].

There have been some novel approaches to address the challenges associated with anesthesia equipment, many led by clinicians with experience of working in low-incomes countries. Two companies have developed anesthesia delivery systems based on the oxygen concentrator (Gradian Health Systems 'Universal Anaesthesia Machine' www.gradianhealth.org and Diamedica Medical Equipment www.diamedica.co.uk). It would be helpful if other larger equipment companies could follow their lead. Lifebox Foundation is a charity that has been established to promote safer surgery, including access to pulse oximetry, and the education and training to sustain this (www. lifebox.org). Based on existing oximetry technologies, the Lifebox Foundation developed specifications for a robust, low-cost and high-quality oximeter specifically customized for use in low- and middle-income countries. An international procurement process was led by the WFSA, and a pooled purchasing contract was developed, in effect combining hospitals to increase market share. A company realizing that the market place is thousands rather than tens should be encouraged to invest in this area. Recent clinical testing confirmed the Lifebox pulse oximeter meets current USA Food and Drug Administration standards for accuracy, supporting the development of affordable monitoring equipment without compromising standards [74]. Over 7,000 units have now been distributed to over 90 countries in conjunction with dedicated training programs.

Other innovative technologies have also been developed, such as mobile phone oximeters, some of which are seeking regulatory clearance for medical use [75]. In order to improve anesthesia safety on a population basis, these novel initiatives need to be scaled up in countries where resources are lacking, and their practicality awaits day-today testing in that environment.

Most anesthesia can fortunately be performed with a simple list of drugs, and the WHO List of Essential Medicines makes a start in this direction, although access to opioids and other analgesic agents needs to be considered as integral to anesthesia [76]. The 2013 Essential 
Medicines List omitted thiopentone and ether, although they are still widely used in a number of LICs. Halothane and ketamine are far from ideal agents, but they are the mainstay of anesthesia provision in many LICs; it is essential that pharmaceutical companies continue to produce these agents and that procurement processes are in place to maintain supplies of them.

\section{Improving the Quality of Existing Services}

Healthcare systems are complex, and existing healthcare services need to be improved at national and local levels, with international support sensitive to local context. Running a national anesthesia service requires training and accreditation systems. It also requires effectively managed hospitals with appropriate facilities to support surgery, and with reliable procurement systems to maintain supplies of essential drugs and equipment at a local level. Local governance procedures are required to ensure appropriate use of resources and adequate numbers of trained staff to fill service rotas and to service and repair equipment when required. When drugs run out or there is no blood for transfusion, how can an anesthesia system function or save lives? Such 'administrative' failures have been identified as a direct cause of perioperative mortality [8-11] and need to be addressed at every level to improve anesthesia outcomes [15••].

Productivity in operating theatres in low-income countries is typically very low, with patients waiting on the ward for treatment despite lists that often start late and finish early. Well-run hospitals in LIC are characterized by clear institutional leadership and goals, adoption of standardized care protocols and processes for procurement, effective management of human resources, structured training programs, measurement of outcomes with reporting of adverse events and good financial oversight [77]. Such institutions may serve as models for others to follow.

Quality improvement initiatives based on long-term institutional partnerships can help improve existing services and have been championed by The UK Tropical Health Education Trust (www.THET.org) and the UK All Parliamentary Group on Global Health [78, 79]. The partnership formed between the Kybele Foundation in the USA and the Ghana Health Service resulted in a $34 \%$ reduction in maternal mortality and $36 \%$ reduction in stillbirth at the Ridge Regional Hospital in Accra between 2007 and 2009, despite an increase in activity at the hospital [80••]. Improvement activities were focused on system failures and used local personnel to implement changes, with tri-annual multidisciplinary visits lasting 1-2 weeks to provide coaching and feedback. Long-term volunteering with organizations such as Voluntary Service
Overseas (VSO) (www.vso.org.uk) offers important opportunities for training and quality improvement [81]. Long-term sustainable impact is increasingly the focus of short-term surgical missions [82].

The WHO Patient Safety Second Global Patient Safety Challenge 'Safe Surgery Saves Lives' highlighted the avoidable harm associated with surgery and anesthesia in the global population and led to the publication of WHO Guidelines for Safe Surgery [33]. One of the main outputs of the Patient Safety Challenge was the Surgical Safety Checklist, which for the first time, included pulse oximetry as a standard of care recommended by the WHO. Implementation of the checklist (including pulse oximetry) has been shown to improve outcomes associated with surgery in all healthcare settings, including in LICs [83-85]. A recent systematic review has suggested that in high-income settings, use of the surgical checklist improves outcomes through improved teamwork and communication [86], although compliance with the checklist items, particularly by medical teams, and integration into work practices is challenging [87-89]. Conversely, the benefits of the checklist in LICs may be influenced by the availability of resources, and lack of resources may act as a significant barrier to implementation $[85,90]$. In such settings, it remains to be seen whether local checklist adaptation with progressive implementation might provide the necessary stimulus to support system-wide improvements, for example, the development of blood transfusion services or antibiotic supply chains.

Many international organizations have made important contributions to improvements in anesthesia safety in LIC, but as witnessed in other areas of development, it is important to make sure that these efforts are coordinated and align with the needs of local clinicians. In anesthesia, international organizations such as the WFSA have a role to play in coordinating these efforts.

\section{Conclusion}

In many countries' anesthesia services are considerably underdeveloped and represent a significant risk to patients. The detail and size of the problem have been described in many studies over the last 2 decades. Our specialty needs to make the case for investment in surgical services with those who control healthcare planning and budget allocations at all levels. Training needs to be recognized as a key component of anesthesia, with appropriate investment in time and resources-this requires support from international healthcare bodies, with encouragement from overseas partnerships in collaborative ways. Basic drug and equipment supplies need to be reliable and cheap, with clear supply chains. Healthcare planners need to consider 
how low-cost anesthesia machines can be designed and manufactured with the needs of the remote hospital in mind. Existing services can be strengthened through longterm partnerships between professional organizations and institutions and by adopting formal quality improvement processes. A coordinated message is required at local, national and international levels; without this, anesthesia services in LICs will not improve and could well continue to deteriorate over the next decade.

\section{Compliance with Ethics Guidelines}

Conflict of Interest Isabeau Walker is Vice President of the Association of Anaesthetists of Great Britain and Ireland (AAGBI), a Trustee of Lifebox Foundation and a member of the World Federation of Societies of Anaesthesiologists (WFSA) Executive Committee. Tom Bashford is a member of the Lifebox Foundation Education Board, an Editorial Advisor to Open Health Data and is a returned Voluntary Service Overseas (VSO) volunteer. J. Edward Fitzgerald declares that he has no conflict of interest. Iain Wilson is a former President of the AAGBI, a Trustee of Lifebox Foundation and a member of the World Federation of Societies of Anaesthesiologists (WFSA) Executive Committee.

Human and Animal Rights and Informed Consent This article does not contain any studies with human or animal subjects performed by any of the authors.

\section{References}

Papers of particular interest, published recently, have been highlighted as:

- Of importance

- Of major importance

1. Trent JC, Gaster RN. Anesthetic deaths in 54,128 consecutive cases. Ann Surg. 1944;119:954-8.

2. Beecher HK, Todd DP. A study of the deaths associated with anesthesia and surgery, bases on a study of 599,548 anesthesias in ten institutions 1948-1952 inclusive. Ann Surg. 1954;140:2-34.

3. Macintosh RR. Deaths under anaesthetics. $\mathrm{Br}$ J Anaesth. 1949;21:107-36.

4. Committee on Quality of Health Care in America IoM. In: Kohn L, Corrigan J, Donaldson M, editors. To err is human: building a safer health system. Washington, DC: National Academy Press; 1999. p. 241.

5. Buck N, Devlin HB, Lunn JN. The report of a confidential enquiry into perioperative deaths. London: Nuffield Provincial Hospitals Trust and the King's Fund; 1987.

6. Eichorn JH. Prevention of intraoperative anesthesia accidents and related severe injury through safety monitoring. Anesthesiology. 1989;70:572-7.

7. • Bainbridge D, Martin J, Arango M, Cheng D, for the Evidencebased Peri-operative Clinical Outcomes Research (EPiCOR) Group. Perioperative and anaesthetic-related mortality in developed and developing countries: a systematic review and metaanalysis. Lancet. 2012;380:1075-81. Systematic review of anesthesia outcomes reported from the 1970s to 2011, showing how anesthesia mortality has improved in countries with a high development index, but not in those with a low development index.
8. Heywood AJ, Wilson IH, Sinclair JR. Perioperative mortality in Zambia. Ann R Coll Surg Engl. 1989;71:354-8.

9. Hansen D, Gausi SC, Merikebu M. Anaesthesia in Malawi: complications and deaths. Trop Doct. 2000;30:146-9.

10. Glenshaw M, Madzimbamuto FD. Anaesthesia associated mortality in a district hospital in Zimbabwe: 1994 to 2001. Cent Afr J Med. 2005;51:39-44.

11. Ouro-Bang'na Maman AF, Tomta K, Ahouangbvi S, Chobli M. Deaths associated with anaesthesia in Togo, West Africa. Trop Doct. 2005;35:220-2.

12. Enohumah KO, Imarengiaye CO. Factors associated with anaesthesia-related maternal mortality in a tertiary hospital in Nigeria. Acta Anaesthesiol Scand. 2006;50:206-10.

13. Walker IA, Wilson IH. Anaesthesia in developing countries-a risk for patients. Lancet. 2008;371:968-9.

14. Fenton P, Whitty CJM, Reynolds F. Caesarean section in Malawi: prospective study of early maternal and perinatal mortality. BMJ. 2003;327:587-92.

15. $\bullet$ Department of Health, Republic of South Africa. Saving mothers 2008-2010: Fifth report on the confidential enquiries into maternal deaths in South Africa. Anesthetic-related deaths. 2012 Ch 7 p. 124 http://www.doh.gov.za/docs/reports/2012/Report_ on_Confidential_Enquiries_into_Maternal_Deaths_in_South_ Africa.pdf. Accessed 15 Dec 2013. Highlights preventable causes of anesthesia-related maternal deaths in rural hospitals.

16. $\bullet$ Weiser TG, Regenbogen SE, Thompson KD et al. An estimation of the global volume of surgery: a modelling strategy based on available data. Lancet. 2008;372:139-44 Describes the deficit in surgical provision in low-income countries.

17. Galukande M, von Schreeb J, Wladis et al. Essential surgery at the district hospital: a retrospective descriptive analysis in three African countries. PLoS Med 2010;7:e1000243.

18. Lavy C, Sauven K, Mkandawire N, et al. State of surgery in tropical Africa: a review. World J Surg. 2011;35:262-71.

19. - Walker IA, Obua AD, Mouton F, Ttendo S, Wilson IH. Paediatric surgery and anaesthesia in south-western Uganda: a crosssectional survey. Bull World Health Organ. 2010;88:897-906 An account of the low volume of surgery performed in rural hospitals.

20. Petroze RT, Groen RS, Niyonkuru F, et al. Estimating operative disease prevalence in a low-income country; results of a nationwide population survey in Rwanda. Surgery. 2013;153:457-64.

21. • Groen RS, Samai M, Stewart K-A et al. Untreated surgical conditions in Sierra Leone: a cluster randomised, cross-sectional, country-wide survey. Lancet 2012;380:1082-87 Describes a method of assessing the unmet surgical need in rural populations.

22. Stewart K-A, Groen RS, Farahzad MM, et al. Traumatic injury in Sierra Leone: results from a nationwide survey. JAMA. 2013;148:463-9.

23. Zafar SN, Fatmi A, Iqbal, et al. Disparities in access to surgical care within a lower income country: an alarming inequity. World J Surg. 2013;37:1470-7.

24. Reshamwalla S, Gobeze AA, Ghosh S, et al. Snapshot of surgical activity in rural Ethiopia: is enough being done? World J Surg. 2012;36:1049-55.

25. - Cavallaro FL, Cresswell JA, Franca GVA et al. Trends in caesarean delivery by country and wealth quintile: cross-sectional surveys in southern Asia and sub-Saharan Africa. Bull World Health Organ 2013; 91:914-22. Highlights the contribution of lack of access to surgery to poor maternal outcomes.

26. - Fenton PM. The epidemiology of district surgery in Malawi: a two-year study of surgical rates and indices in rural Africa. East Central Afr J Surg 2011;16(3). http://www.ajol.info/index.php/ ecajs/article/view/74250. Accessed 15 Dec 2013. Description of a method to track surgical rates, relative to CS rates. 
27. - Kushner A, Groen RS, Kingham TP. Percentage of cesarean sections among total surgical procedures in sub-Saharan Africa: possible indicator of the overall adequacy of surgical care. World J Surg 2010; 34:2007-08 Description of a method to track surgical rates, relative to $C S$ rates.

28. Hughes CD, McClain CD, Hagander L, et al. Ratio of cesarean deliveries to total operations and surgeon nationality are potential proxies for surgical capacity in central Haiti. World J Surg. 2013;37:1526-9.

29. Debas HT, Gosselin R, McCord C, Thind A. Surgery. In: Jamison DT, Breman JG, Measham AR, et al., editors. Disease control priorities in developing countries, vol. 2. New York: The World Bank/Oxford University Press; 2006. p. 1245-60.

30. Murray CJ, Vos T, Lozano R, et al. Disability adjusted life years (DALYs) for 291 diseases and injuries in 21 regions, 1990-2010: a systematic analysis for the Global Burden of Disease Study 2010. Lancet. 2010;380:2197-223.

31. • Grimes CE, Henry JA, Maraka J et al. Cost effectiveness of surgery in low- and middle-income countries: a systematic review. World J Surg 2014;38:252-263. Systematic review to describe the cost effectiveness of surgery.

32. • Merry AF, Cooper JB, Soyannwo O et al. International standards for a safe practice of anesthesia 2010. Can J Anesth 2010;57:1027-34 Defines minimum standards for provision of safe anesthesia at different levels of the hospital.

33. WHO Guidelines for Safe Surgery (2009) Safe Surgery Saves Lives. WHO Press: World Health Organization, Geneva. http:// whqlibdoc.who.int/publications/2009/9789241598552_eng.pdf. Accessed 15 Dec 2013.

34. Hodges SC, Mijumbi C, Okello M, et al. Anaesthesia services in developing countries: defining the problems. Anaesthesia. 2007; 62:4-11.

35. WHO. Emergency and essential surgical care. Quality and safety tools. http://www.who.int/surgery/publications/immesc_quality_ tools/en/index.html. Accessed 15 Dec 2013.

36. Choo S, Perry H, Hesse AA, et al. Assessment of capacity for surgery, obstetrics and anaesthesia in 17 Ghanaian hospitals using a WHO assessment tool. Trop Med Int Health. 2010;15:1109-15.

37. Sherman L, Clement PT, Cherian MN, et al. Implementing Liberia's poverty reduction strategy: an assessment of emergency and essential surgical care. Arch Surg. 2011;146:35-9.

38. Notrica MR, Evans FM, Knowlton LM, Kelly McQueen KA. Rwandan surgical and anesthesia infrastructure: a survey of district hospitals. World J Surg. 2011;35:1770-80.

39. Spiegel DA, Choo S, Cherian M, et al. Quantifying surgical and anesthetic availability at primary health facilities in Mongolia. World J Surg. 2011;35:272-9.

40. Linden AF, Sekidde FS, Galukande M, et al. Challenges of surgery in developing countries: a survey of surgical and anesthesia capacity in Uganda's public hospitals. World J Surg. 2012;36:1056-65.

41. Chao TE, Burdic M, Ganjawalla K, et al. Survey of surgery and anesthesia infrastructure in Ethiopia. World J Surg. 2012;36: 2545-53.

42. Solis C, León P, Sanchez N, et al. Nicaraguan surgical and anesthesia infrastructure: survey of Ministry of Health hospitals. World J Surg. 2013;37:2109-21.

43. Lebrun DG, Dhar D, Sarkar MI, et al. Measuring global surgical disparities: a survey of surgical and anesthesia infrastructure in Bangladesh. World J Surg. 2013;37:24-31.

44. Vo D, Cherian MN, Bianchi S et al. Anesthesia capacity in 22 low and middle income countries. J Anesth Clin Res 2012;3:4. doi:10.4172/2155-6148.1000207.

45. Hoyler M, Leon P, Sanchez, et al. Nicaraguan surgical and anesthesia infrastructure: survey of Ministry of Health hospitals. World J Surg. 2013;37:2109-12.
46. Bowman KG, Jovic G, Rangel S, Berry WR, Gawande AA. Pediatric emergency and essential surgical care in Zambian hospitals: a nationwide study. J Pediatr Surg. 2013;48:1363-70.

47. Groen RS, Kamara TB, Dixon-Cole R, et al. A tool and index to assess surgical capacity in low income countries: an initial implementation in Sierra Leone. World J Surg. 2012;36:1970-7.

48. Henry JA, Windapo O, Kushner AL, Groen RS, Nwomeh BC. A survey of surgical capacity in rural southern Nigeria: opportunities for change. World J Surg. 2012;36:2811-8.

49. Kushner A, Groen RS, Kamar TB, et al. Assessment of pediatric surgery capacity at Government Hospitals in Sierra Leone. World J Surg. 2012;36:2554-8.

50. Jochberger S, Ismailova F, Lederer W, et al. Anesthesia and its allied disciplines in the developing world: a nationwide survey of the Republic of Zambia. Anesth Analg. 2008;106:942-8.

51. Jochberger S, Bataar O, Mendsaikhan N, et al. Anesthesia care in a medium-developed country: a nationwide survey of Mongolia. J Clin Anesth. 2010;22:443-9.

52. Size M, Soyannwo OA, Justins DM, et al. Pain management in developing countries. Anaesthesia. 2007;62(suppl 1):38-43.

53. - Funk LM, Weiser TG, Berry WR et al. Global operating theatre distribution and pulse oximetry supply: an estimation from reported data. Lancet. 2010;376:1055-61 Estimation of global need in terms of surgical and anesthesia workforce and infrastructure.

54. Hoyler M, Finlayson SR, McClain CD et al. Shortage of doctors, shortage of data: a review of the global surgery, obstetrics, and anesthesia workforce literature. World J Surg. 2014;38:269-80.

55. Chen L, Evans T, Anand S, et al. Human resources for health: overcoming the crisis. Lancet. 2004;364:1984-90.

56. Hongoro C, McPake B. How to bridge the gap in human resources for health. Lancet. 2004;364:1451-6.

57. Anand S, Bärnighausen T. Human resources and health outcomes: cross-country econometric study. Lancet. 2004;364: 1603-9.

58. Kruk ME, Wladis A, Mbembati N, et al. Human resource and funding constraints for essential surgery in district hospitals in Africa: a retrospective cross-sectional survey. PLoS Med. 2010;7:e1000242. doi:10.1371/journal.pmed.1000242.

59. Ferrinho P, Sidat M, Goma F, Dussault G. Task-shifting: experiences and opinions of health workers in Mozambique and Zambia. Human Resour Health. 2012;10:34.

60. The World Bank. Health Expenditure per capita (current US\$). http://data.worldbank.org/indicator/SH.XPD.PCAP. Accessed 15 Dec 2013.

61. United Nations. Health in the post-2015 Development Agenda. http://www.worldwewant2015.org/health. Accessed 15 Dec 2013.

62. - Meara JG, Hagander L, Leather AJ. Surgery and global health: a Lancet Commission. Lancet 2014;383:12-13. Description of priority areas to improve access to safe surgery and anesthesia.

63. Disease Control Priorities Project http://www.dcp2.org/page/ main/Home.html. Accessed 15 Dec 2013.

64. Mock C, Cherian M, Juillard C. Developing priorities for addressing surgical conditions globally: furthering the link between surgery and public health policy. World J Surg. 2010;34:381-5.

65. Gosselin R, Ozgediz D, Poenaru D. A square peg in a round hole? Challenges with DALY-based "Burden of Disease" calculations in surgery and a call for alternative metrics. World J Surg. 2013;13:2507-11.

66. - Newton M, Bird P. Impact of parallel anesthesia and surgical provider training in sub-Saharan Africa: a model for a resourcepoor setting. World J Surg. 2010;34:445-52 Description of a successful nurse anesthesia training program, linked to a sustained increase in surgical activity. 
67. - Whitaker DK, Walker I. College supports Uganda Fellowship Programme. Bull Roy Coll Anaesth 2012;73:43-5 http://rcoa.ac. uk/system/files/CSQ-Bulletin73_0.pdf. Accessed 15 Dec 2013. Description of successful institutional partnerships.

68. - Lipnick M, Mijumbi C, Dubowitz G et al. Surgery and anesthesia capacity-building in resource-poor settings: description of an ongoing academic partnership in Uganda. World J Surg. 2013;37:488-97 Description of successful institutional partnerships.

69. AAGBI. The SAFE obstetric anaesthesia course. http://www. aagbi.org/international/international-relations-committee/ refresher-courses. Accessed 15 Dec 2013.

70. - Canadian Anaesthesiologists' Society International Education Foundation (CASIEF) Mission in Rwanda https://www.cas.ca/ English/CASIEF-Rwanda. Accessed 15 Dec 2013. Description of successful institutional partnerships.

71. - Kinnear JA, Bould MD, Ismailova F, Measures E. A new partnership for anesthesia training in Zambia: reflections on the first year. Can J Anaesth. 2013;60:484-91 Description of successful institutional partnerships.

72. International Organization for Standardization. ISO 8835-7:2011. Inhalational anaesthesia systems-part 7: Anaesthetic systems for use in areas with limited logistical supplies of electricity and anaesthetic gases. www.iso.org. Accessed 15 Dec 2013.

73. Duke T, Graham SM, Cherian MN, et al. Oxygen is an essential medicine: a call for international action. Int J Tuberc Lung Dis. 2010;14:1362-8.

74. Dubowitz G, Breyer K, Lipnick M, Sall JW, Feiner J, Ikeda K, Bickler PE. Accuracy of the Lifebox pulse oximeter during hypoxia in healthy volunteers. Anaesthesia. 2013;68(12):1220-3.

75. Ansermino JM. Universal access to essential vital signs monitoring October. Anesth Analg. 2013;117:883-9.

76. WHO Model lists of essential medicines http://www.who.int/ medicines/publications/essentialmedicines/en/. Accessed 15 Dec 2013.

77. Funk LM, Conley DM, Berry WR, Gawande AA. Hospital management practices and availability of surgery in sub-Saharan Africa: a pilot study of three hospitals. World J Surg. 2013;37:2520-8

78. Parry EHO, Percy DB. Anaesthesia and hospital links: supporting healthcare through South-North hospital partnerships. Anaesthesia. 2007;62(suppl 1):11-4.
79. UK Government. All parliamentary group on global health. improving health at home and abroad. How overseas volunteering from the NHS benefits the UK and the world. 2013. www.appgglobalhealth.org.uk. Accessed 15 Dec 2013.

80. • Srofenyoh E, Ivester T, Engmann C et al. Enhancing obstetric and neonatal care in a regional hospital in Ghana via continuous quality improvement. Int J Gyn Obstr 2012;116:17-21 Description of successful institutional partnerships inked to a quality improvement program.

81. Bashford T. Quality improvement in low resource settings: an Ethiopian experience. Br J Hosp Med. 2013;74:286-8.

82. Patel PB, Hoyler M, Maine R, et al. An opportunity for diagonal development in global surgery: cleft lip and palate care in resource-limited settings. Plast Surg Int. 2012;2012:892437. doi:10.1155/2012/892437.

83. Haynes AB, Weiser TG, Berry WR, et al. Safe Surgery Saves Lives Study Group. A surgical safety checklist to reduce morbidity and mortality in a global population. $\mathrm{N}$ Engl $\mathrm{J}$ Med. 2009;360:491-9.

84. Kwok AC, Funk LM, Baltaga R, et al. Implementation of the World Health Organization surgical safety checklist, including introduction of pulse oximetry, in a resource-limited setting. Ann Surg. 2013;257:633-9.

85. Yuan CT, Walsh D, Tomarken JL, et al. Incorporating the World Health Organization Surgical Safety Checklist into practice at two hospitals in Liberia. J Comm J Qual Patient Saf. 2012;38:254-60.

86. Russ S, Rout $\mathrm{S}$, Sevdalis N, et al. Do safety checklists improve teamwork and communication in the operating theatre? A systematic review. Ann Surg. 2013;258:856-71.

87. van Klei WA, Hoff RG, van Aarnhem EE, et al. Effects of the introduction of the WHO "Surgical Safety Checklist" on inhospital mortality: a cohort study. Ann Surg. 2012;255:44-9.

88. Vats A, Vincent CA, Nagpal K, et al. Practical challenges of introducing WHO surgical checklist: UK pilot experience. BMJ. 2010;340:b5433. doi:10.1136/bmj.b5433.

89. Pickering SP, Robertson ER, Griffin D, et al. Compliance and use of the World Health Organization checklist in UK operating theatres. Br J Surg. 2013;100:1664-70.

90. Aveling EL, McCulloch P, Dixon-Woods M. A qualitative study comparing experiences of the surgical safety checklist in hospitals in high-income and low-income countries. BMJ Open. 2013;3:e003039. doi:10.1136/bmjopen-2013-003039. 